\title{
Epidemiological features and associated factors of pulmonary tuberculosis with positive microscopy in the infectious diseases unit at the $\mathrm{CHU}$ of Brazzaville
}

\begin{abstract}
Aim: Describe the epidemiological aspects of patients with positive microscopic pulmonary tuberculosis and identify associated factors.

Methodology: A retrospective descriptive and analytical study of patients admitted for pulmonary tuberculosis with a positive microscopy between July 2014 and July 2016.

Results: Forty-four patients were included ( $15.0 \%$ of admissions) with a mean age of 42.5 \pm 8.13 females $(n=27,61.3 \%)$. The sex ratio was 0.6 . Patients had no jobs $(n=24,54 \%)$, attending school $(\mathrm{n}=25,56.1 \%)$, residing in the city $(\mathrm{n}=35,5 \%)$, unmarried $(\mathrm{n}=25$, $56.8 \%$ ). HIV infection was heterosexual in 43 patients (97.7\%). This was HIV 1 in $43 \%$ of cases. HIV infection was discovered before tuberculosis in 24 patients (54.5\%). Fever and cough were the most frequent reasons for consultation in 37 patients $(84.1 \%)$ and 38 patients $(86.4 \%)$. Consultation of patients was carried out in more than two weeks in 25 patients $(56.8 \%)$. Thirty-two patients $(72.7 \%)$ were severely weakened immune system. Pediatric chest x-ray showed a cave in 16 patients $(36.4 \%)$, most of whom were new cases of tuberculosis $(n=38,86.4 \%)$. Tuberculosis treatment was directly observed in 19 patients $(43.2 \%)$ and 37 patients $(84.1 \%)$ were on the front line of antiretroviral therapy. The mean time to onset of BK treatment was $15.43 \pm 71$. Immune Restoration Syndrome was observed in six patients. The mean hospital stay was $16.55 \pm 11$ days. Negative sputum was obtained in more than 2 weeks in $27.3 \%$ of cases. Fifteen patients $(34.5 \%)$ died for respiratory distress $(\mathrm{n}=8,53.3 \%)$ and anemia $(\mathrm{n}=7,46.6 \%)$. Immunosuppression influenced prognosis in these patients $(\mathrm{p}=0.003)$.
\end{abstract}

Conclusion: The lethality of bacilliform tuberculosis in HIV positive patients remains high in our series in a context of immune depression. Early detection and the care of this infection may improve the prognosis of tuberculosis patients.

Keywords: tuberculosis, microscopy, HIV, CHU
Volume 4 Issue 5 - 2017

\author{
Ossibi lbara RB, Okemba Okombi FH, Niama \\ RF, Bemba ELP, Doukanga T, Boumandouki JPC, \\ Ngoyi Ontsira EN and Obengui \\ Marien Ngouabi University, Congo
}

Correspondence: Bienvenu Rolland Ossibi lbara, Marien Ngouabi University, CHU-Brazzaville, BP: 1846, Brazzaville, Congo, Email bienvenu_07@yahoo.fr

Received: September 16, 2017 | Published: November 15, 2017
Abbreviations: AEG; general state alteration, ARVT; antiretroviral therapy, $\mathrm{AFB}$; acid-fast bacilli, $\mathrm{BK}$; koch bacilli, CD4; lymphocyte $\mathrm{CD} 4, \mathrm{CHU}$; university hospital center, $\mathrm{CHUB}$; university hospital center at brazzaville, DOT; direct observed treatment, HIV; human immunodeficiency virus, TDR; rapid diagnostic test, WHO; world health organization

\section{Introduction}

Tuberculosis is the only opportunistic infection (OI) that represents a potential threat for public health for both HIV-infected and non HIVinfected populations. It is the most frequent $\mathrm{IO}$ at the planetary level and is responsible for one-quarter of HIV-related deaths. ${ }^{1}$ Within the treatment facilities, positive microscopic tuberculosis constitutes a risk of nosocomial transmission for patients and caregivers.In 2013, 1.1 million (13\%) out of 9 million people contaminated by TB worldwide were HIV-positive. The African Region includes 78\% of the estimated number of TB cases infected by HIV. ${ }^{2}$ The majority of these patients living in socio-economic precariousness conditions are in sub-Saharan Africa where promiscuity remains the factor favoring the transmission of $\mathrm{BK}$ in the bacilliform patients. ${ }^{3} \mathrm{~A}$ familial positive microscopy pulmonary tuberculosis depicted among contact subjects around a contagious index case in West Africa is a good illustration. ${ }^{4}$

The peculiarity of positive microscopic pulmonary tuberculosis in patients living with HIV lies in the possibilities of contamination of the surrounding and the negativity of the sputum condition necessary for the introduction of highly active antiretroviral combination therapy. In Congo, in 2013, 10.699 patients with tuberculosis of all forms were depicted including 4178 tuberculosis cases with positive microscopy. All of these data are compiled according to the United Nations system, but few studies conducted in hospitals provide information on the prevalence of bacillary tuberculosis in the HIVand weakened immune system population. This is the reason why we choose the University Hospital Center of Brazzaville because it is a national reference center and includes expertise and appropriate instruments to cope with the diagnosis and the care of positive microscopic pulmonary tuberculosis patients. This study aims to describe the epidemiological features of patients with positive HIVinfected tuberculosis and to investigate the factors that may influence the therapeutic outcome. We hypothesized that positive microscopic pulmonary tuberculosis represents a risky factor to the HIV patients. 


\section{Patients and methods}

The present study was conducted at infectious diseases unit at CHUB and includes 44 out of 293 patients undergoing pulmonary tuberculosis cases. This is a retrospective descriptive and analytical study in the infectious disease unit for patients admitted between July 1, 2014 and July 31, 2016, i.e. 24 months of study. The study was carried out based on the exploitation of hospitalization documents and medical files of hospitalized patients in infectious diseases unit during the study period. The present study patients are at least 18 years of age regardless of gender, weakened immune system by HIV regardless of type, whether or not receiving highly active antiretroviral therapy, with positive microscopic pulmonary tuberculosis, sputum examination for AFBs by Ziehl Neelsen staining performed at the CHUB Laboratory of Bacteriology-Virology is positive with a bacterial density of at least 10,000 bacteria per $\mathrm{ml}$ in all cases.

In fact, all these patients provide a free consent for their contribution to the present study as informant case studies further to an interview form. Under this survey, we resort to DOT to evaluate the observance and the efficiency of the therapy administered to patients. In addition, we also pay attention to the deadline of consultation in order to determine the effect of the consultation upon the disease case study. Finally, we evaluate the consideration of the HIV treatment further to the beginning of tuberculosis treatment.

\section{Variables of studies}

The variables used for this study cover age, sex, occupation, socioeconomic status, place of residence, reasons for consultation and consultation time, WHO classification, bacterial density, chest x-rays, HIV serology, the number of CD4 lymphocytes, duration of antituberculosis treatment, time to initiation versus antiretroviral therapy, cure, relapse, reprocessing or treatment completed, death, and cause of death.

\section{Operational definition of cases $^{5}$}

Positive microscopy tuberculosis: a bacteriologically confirmed case of tuberculosis where the positivity of the biological sample has been established by microscopic examination of smears, culture or TDR approved by WHO (i.e. at least 2 smear-positive, 1 positive smear with of pulmonary radiographic abnormalities consistent with active tuberculosis, i.e. 1 positive smear and positive culture).

Healing: a tuberculosis patient who has been confirmed bacteriologically at the start of treatment has negative results during the last month of treatment and at least once before.

Treatment completed: Tuberculosis patient completed treatment with no signs of failure, but no data showing that smear or culture results were negative during the last month of treatment and at least once, either because the tests have not been performed or because the results are not available.

Death: Tuberculous patient dies for some reasons during treatment or before starting treatment.

The socio-economic precariousness was defined by the presence of at least one of the following items:

a. Unemployment, homeless, household income $<535 € /$ month, illegal immigrant.

\section{Data analysis}

The data were formatted on the ESOPE software, exported on EPI info 2000 version 3.5 with the determination of the descriptive and analytical statistics (qualitative variables in numbers and percentages and quantitative variables in medians and interquartile intervals) for all the subjects. For all tests, the significance level was set at 5\%.

\section{Results}

This study allowed us to collate 293 cases of pulmonary tuberculosis associated with HIV infection of type 1 out of which 44 HIV and Tuberculosis infected patients had a positive microscopy with $15,0 \%$ of the admissions. This concerns young patients aged 42.5 \pm 8.13 years for males $(n 17,38.63 \%)$ and females $(n=27 ; 61.36 \%)$. The sex ratio was 0.6. The socio-occupational status included the jobless $(n=24,54 \%)$, public officer $(n=9,20.5 \%)$, Pupils/students $(\mathrm{n}=8,18.1 \%)$. Thirty patients were in socio-economic precariousness $(68.2 \%)$. Literate patients $(\mathrm{n}=25,56.1 \%)$, urban resident patients $(\mathrm{n}=35,79.5 \%)$ and married patients $(\mathrm{n}=15,34.1 \%)$.

HIV infection was heterosexually transmitted in 43 patients (97.7\%). This was HIV1 (43\%) of the cases. HIV infection was discovered before tuberculosis in 24 patients $(54.5 \%)$. Fever and cough were the main reasons for consultation respectively in 37 patients $(84.1 \%)$ and 38 patients $(86.4 \%)$ (Table 1$)$.

Table I Distribution of patients based on consultation reasons.

\begin{tabular}{lll}
\hline Symptoms & $\mathbf{n}$ & $\%$ \\
\hline Cough & 38 & $86.40 \%$ \\
AEG & 38 & $86.40 \%$ \\
Fever & 37 & $84.10 \%$ \\
Chest pain & 7 & $15.90 \%$ \\
Dyspnea & 6 & $13.60 \%$ \\
Hemoptysis & 5 & $11.40 \%$ \\
Others & 5 & $11.40 \%$
\end{tabular}

The consultation took more than two weeks in 25 patients (56.8\%). Thirty-two patients $(72.7 \%)$ were in stage III of the WHO and 4 patients (9.1\%) in stage IV. Twenty-eight patients $(37.8 \%)$ had CD4 counts below $200 / \mathrm{mm}^{3}$. Radiographic images were represented by caves (n $=16,36.4 \%)$, micro nodular opacities $(n=10 ; 22.7 \%)$. These were new cases of tuberculosis $(n=38 ; 86.4 \%)$, retreatment $(n=3 ; 6.81 \%)$. Tuberculosis treatment was directly observed in 19 patients $(43.2 \%)$ and 37 patients $(84.1 \%)$ were on the front line of antiretroviral therapy. The mean time to initiation of BK therapy was $15.43 \pm 7.1$ days. Immune restoration syndrome was observed in six patients. The mean hospital stay was $16.55 \pm 11$ days. Negative sputum was obtained in more than two weeks in $27.3 \%$ of cases. Fifteen patients (34.5\%) died. The causes of death were: respiratory distress $(n=8,53.3 \%)$, anemia $(\mathrm{n}=7,46.6 \%)$.Advanced immunosuppression influenced prognosis in these patients $(\mathrm{P}=0.003)$ (Table 2$)$.

\section{Discussion}

In a 24 month retrospective study carried out in the Infectious Diseases unit at the CHU of Brazzaville, 44 cases of positive microscopy tuberculosis were predominantly collected in patients with a mean age of $42.5 \pm 8.13$ years, living in a socio-economic 
precariousness situation, infected with HIV1 and died in most cases. This precarious situation is one of the risk factors for the abandonment of anti-bacillary treatment in patients with positive microscopy pulmonary tuberculosis ${ }^{6}$. The prevalence of positive microscopic tuberculosis in the weakened immune system population with HIV type 1 in our study is high (15.01\%). It is rather high (32.9\%) in the unit of Pneumophtisiology of the CHU of Brazzaville 7 . It is estimated that an untreated bacillary patient can contaminate on average more than 10 contacts per year and more than 20 contacts during the natural history of his disease until death. ${ }^{8}$ It is still predominantly female subjects related to the feminization of HIV infection in a disadvantaged and weakened social stratum. ${ }^{9,10}$ Promiscuity remains the main factor favoring BK contamination in single patients who are heterosexually infected with HIV as described in the literature. ${ }^{10}$ Tuberculosis occurred at any stage of immunosuppression to our patients since most of them had contracted Mycobacterium tuberculosis after HIV infection. This case is similar to the situation in Africa. ${ }^{10,11}$ These patients are still deeply weakened immune system and consult late for fever developing in isolated case or associated with a chronic cough. These long consultation periods are known in sub-Saharan Africa. ${ }^{9,10,12,13}$ Indeed, the poverty of the target populations delays hospital admissions since patients firstly consult traditionally before being consulted by the specialist services late in the advanced immune depression stage. Social beliefs partly justify this delay in quality care. Cavern images were frequently found in our patients at the frontal chest $\mathrm{x}$-ray.

Table 2 Distribution of patients based on associated factors.

\begin{tabular}{|c|c|c|c|c|c|c|c|}
\hline \multirow{3}{*}{ AGE } & \multicolumn{2}{|c|}{ Death } & \multicolumn{2}{|c|}{ No Death } & \multicolumn{2}{|c|}{ Total } & \multirow{3}{*}{$\mathbf{P}$} \\
\hline & $\mathbf{N}$ & $\%$ & $\mathbf{n}$ & $\%$ & $\mathbf{N}$ & $\%$ & \\
\hline & & & & & & & \\
\hline$\leq 50$ years & II & 32.4 & 23 & 67.6 & 34 & 100 & \multirow{2}{*}{0.713} \\
\hline$>50$ years & 4 & 40.0 & 6 & 60.0 & 10 & 100 & \\
\hline SEX & & 0.0 & & 0.0 & & 0 & \multirow{3}{*}{0.645} \\
\hline M & 7 & 41.2 & 10 & 58.8 & 17 & 100 & \\
\hline $\mathrm{F}$ & 8 & 29.6 & 19 & 70.4 & 27 & 100 & \\
\hline Education level & & 0.0 & & 0.0 & & 0 & \\
\hline No schooling & I & 20.0 & 4 & 80.0 & 5 & 100 & 0.646 \\
\hline Students & 10 & 32.3 & 21 & 67.7 & 31 & 100 & 0.73 \\
\hline No idea & 4 & 50.0 & 4 & 50.0 & 8 & 100 & 0.41 \\
\hline WHO classification & & 0.0 & & 0.0 & & 0 & \\
\hline II & 0 & 0.0 & 8 & 100.0 & 8 & 100 & 0.036 \\
\hline III & 12 & 37.5 & 20 & 62.5 & 32 & 100 & 0.49 \\
\hline IV & 3 & 75.0 & 1 & 25.0 & 4 & 100 & 0.11 \\
\hline CD4 $\left(/ \mathrm{mm}^{3}\right)$ & & 0.0 & & 0.0 & & 0 & \\
\hline $0-200$ & 11 & 39.3 & 17 & 60.7 & 28 & 100 & 0.51 \\
\hline $200-350$ & 2 & 15.4 & 11 & 84.6 & 13 & 100 & 0.15 \\
\hline $350+$ & 0 & 0.0 & 1 & 100.0 & 1 & 100 & 0.659 \\
\hline Not indicated & 2 & 100.0 & 0 & 0.0 & 2 & 100 & 0.11 \\
\hline Observance dots & & 0.0 & & 0.0 & & 0 & \\
\hline Yes & 6 & 31.6 & 13 & 68.4 & 19 & 100 & 0.51 \\
\hline No & 6 & 31.6 & 13 & 68.4 & 19 & 100 & 0.51 \\
\hline Not indicated & 3 & 50.0 & 3 & 50.0 & 6 & 100 & 0.394 \\
\hline ARVT & & 0.0 & & 0.0 & & 0 & \\
\hline Yes & 12 & 32.4 & 25 & 67.6 & 37 & 100 & 0.67 \\
\hline No & 3 & 50.0 & 3 & 50.0 & 6 & 100 & 0.39 \\
\hline Not indicated & 0 & 0.0 & 1 & 100.0 & 1 & 100 & 0.659 \\
\hline TOTAL & 15 & 34.1 & 29 & 65.9 & 44 & 100 & \\
\hline
\end{tabular}


In Abidjan, infiltrates and caves were predominantly found in smokers with pulmonary tuberculosis with positive microscopy. ${ }^{14}$ Indeed, the effective cellular immunity produces an antigen-antibody reaction during aggression by Mycobacterium tuberculosis, which is the cause of the formation of an inflammatory granuloma. Secondary tissue necrosis due to Mycobacterium tuberculosis with subsequent excavation is at the cause of the tuberculous caverns. These defense mechanisms against tuberculous infection are disrupted with alteration of cell-mediated immunity. ${ }^{8}$ Immune restoration syndrome was observed in $13.6 \%$ of our patients. IRIS is a common inflammatory disease in patients with severe weakened immune system patients with tuberculosis, but little diagnosed due to lack of a technical plateau. ${ }^{15,16}$ A prospective study of 423 patients in South Africa followed IRIS over a period of six months showed incidence to be $10.4 \%$ and immune restoration syndrome occurred in $75 \%$ of cases within three months of ARV Tinitiation. Tuberculosis was the most common pathology. ${ }^{17}$ The average length of hospital stay in our bacilliform patients seems long. These long durations are classical in sub-Saharan Africa. ${ }^{9,10,13}$

The delay in consultation and the persistence of AFBs in sputumcontrol examinations coupled with advanced immunosuppression, the occurrence of other opportunistic infections as part of the coronary process partly justifies the length of hospital stay. The overall lethality remained high at $35.4 \%$ to our patients who died for respiratory distress and anemic shock respectively in 53.3\% and 46.6\%. HIV and tuberculosis, which mutually accelerate their progression, represent a murderous association. Tuberculosis is the opportunistic infection in AIDS responsible for one quarter of HIV-related deaths. ${ }^{1}$ In order to reduce this high mortality rate, it is also necessary to apply other measures recommended by WHO coined under the acronym "31s" namely "Intensified case finding", "Infection control" and "Isoniazid preventive therapy". ${ }^{1}$ The pejorative role of anemia in AIDS patients in tuberculosis patients is demonstrated in several African series. ${ }^{18}$

\section{Conclusion}

In summary, the majority of positive microscopic pulmonary tuberculosis patients die in anemia and advanced immunosuppression stage. The reduction of this high mortality rate strongly depends on early diagnostic of cases, the management of HIV treatment, and the tuberculosis prevention. The long consultation time and the diagnostic delay are amongst the reasons which justify this high mortality rate.

\section{Acknowledgments}

None.

\section{Conflicts of interest}

The authors report no conflict of interest in relation to this study.

\section{References}

1. Harries AD, Zachariah R, Corbett EL, et al. The HIV-associated tuberculosis epidemic: when will we act. Lancet 375(9729). 2010;19061919

2. WHO Global Tuberculosis Report. World Health Organization, Geneva, Switzerland;2014.
3. WHO Global tuberculosis control: WHO report. World Health Organization, Geneva, Switzerland;2010.

4. Diatta A, Toure NO, Dia Kane Y, et al. Tuberculose familiale: Dépistage parmi les sujets contact autour d'un cas index contagieux. Revue des Maladies Respiratoires. 2007;24(1): 32-40.

5. WHO Guidelines for the programmatic management of drug-resistant tuberculosis. World Health Organization, Geneva, Switzerland;2013.

6. Habibi B, Atmane A, Hammi S, et al. Les facteurs de risques de l'abandon du traitement anti-bacillaire chez les patients atteints de tuberculose pulmonaire à microscopie positive (TPM+). Revue des Maladies Respiratoires. 2016 ;33: A42-A43.

7. Presley BEL, Bopaka RG, Moyikoua R, et al. Tuberculose pulmonaire a Brazzaville en hospitalisation pneumologique: impact du diagnostic tardif a l'infection au VIH sur les anomalies radiologiques. Pan African Medical. 2016;24:259.

8. Styblo K. Epidemiology of tuberculosis selected papers. The Royal Netherlands Tuberculosis Association. 1991;24:53-54.

9. Rolland OBI, Presley BEL, Hardin OOF. Co-infection tuberculoseVIH dans le service des maladies infectieuses du CHU de Brazzaville: prevalence et facteurs associes au deces. Rev Pneumol Trop. $2015 ; 23: 47-52$.

10. Ouedraogo G, Hema A, Boncoungou $\mathrm{K}$, et al. Incidence de la tuberculose activedans une cohorte de personnes infectees par le VIH a l'hopital de jour de Bobo Dioulasso (Burkina-Faso). Rev Pneumol Trop. $2015 ; 24: 48-55$.

11. Ossibi Ibara BH, Bienvenu Rolland FH, Okombi O, et al. Tuberculose pulmonaire associee a l'infection a VIH dans le service des maladies infectieuses du CHU de Brazzaville: prevalence et facteurs associes. $J$ Fran Viet Pneu. 2016 ;20(7): 24-28.

12. Bemba ELP, Horo K, Okombi F. Facteurs influencant le delai de diagnostic de la tuberculose pulmonaire a microscopie positive. Rev Pneumol Trop. 2013;20:22-30.

13. Iliyasu Z, Babashani M. Prevalence and predictors of tuberculosis coinfection among HIV-Seropositive patients Attending the Aminu Kano teaching Hospital, Northern Nigeria. JEpidemiol. 2009;19(2):8187.

14. Koffi MO, Kouassi B, Kone A, et al. Caracteristiques de la tuberculose pulmonaire a microscopie positive chez les sujets tabagique au service de pneumologie du CHU de Cocody a Abidjan. Revue des Maladies Respiratoires. 2015;32:A216-A217.

15. Ossibi Ibara BR, Bemba ELP, Okemba Okombi FA, et al. First documented case of IRIS-Tuberculosis in the infectious diseases department of the University Hospital Center of Brazzaville. J Fran Viet Pneu. 2015;19(6):86-89.

16. Lawn SD, Wilkinson RJ, Lipman MC, Wood R. Immune reconstitution and "unmasking" of tuberculosis during antiretroviral therapy. Am J Respir Crit Care Med. 2008;177(7):680-685.

17. Murdoch MD, Venter WD, Feldman C. Incidence and risk factors for the immune reconstitution inflammatory syndrome in HIV patients in South Africa: a prospective study. AIDS. 2008;22(5):601-610.

18. Diallo A, Baby M, Dembele M, et al. Frequency, risk aversion and prognostic value of anemia associated with HIV/AIDS in adults in Mali. Bull Soc Pathol Exot. 2003;96:123-127. 